\title{
A mineração e suas consequências no município de Pedra Lavrada- PB: uma perspectiva da legislação ambiental
}

\author{
Mining and its consequences in the municipality of Pedra Lavrada-PB: a perspective of \\ environmental legislation
}

\author{
SOUZA $^{1}$, Y. G.; COBEL ${ }^{2}$, J. L. P.; SILVA $^{3}$, J. B. \\ yurigomes.s28@gmail.com
}

\begin{abstract}
Resumo
A mineração é um dos principais motores da economia do Seridó paraibano pois o mesmo detém de um complexo mineralógico propício à exploração. Em Pedra Lavrada-PB, essa atividade proporciona renda e emprego à população. Em virtude de tal prática, contudo, algumas consequências vêm sujeitando os agentes do meio social, bem como os recursos naturais. Logo, a presente pesquisa se propôs a analisar a prática exploratória da mineração por parte dos garimpeiros e suas consequências no município de Pedra Lavrada-PB sob a perspectiva da legislação ambiental. Quanto a metodologia, apoiou-se no levantamento bibliográfico, análise empírica e entendimento da estrutura altimétrica do município de Pedra Lavrada-PB com recorte da área estudada. Constatou-se que embora a mineração seja fundamental para a conjuntura socioeconômica do município, o processo de exploração mineral na lavra do "Alto Feio" representa um trabalho exaustivo e rudimentar, onde ferramentas de trabalho não são adequadas e a proteção do garimpeiro inexiste. Percebeu-se que o meio ambiente vem somando prejuízos em virtude da atividade exploratória na área. Portanto, tem-se a Constituição Federal de 1988 que assegura o meio ambiente ecologicamente equilibrado e regulamenta à sadia manutenção da vida humana.
\end{abstract}

Palavras-chave: Exploração, meio ambiente, constituição federal.

\begin{abstract}
Mining is one of the main engines of the economy of the Seridó Paraíba because it has a mineralogical complex conducive to exploitation. In Pedra Lavrada-PB, this activity provides income and employment to the population. By virtue of such practice, however, some consequences are subjecting agents of the social environment as well as natural resources. Therefore, the present study proposed to analyze the exploratory practice of mining by the garimpeiros and their consequences in the municipality of Pedra Lavrada-PB under the perspective of environmental legislation. Regarding the methodology, it was based on the bibliographical survey, empirical analysis and understanding of the altimetric structure of the Pedra Lavrada-PB municipality with a cut of the studied area. It was verified that although the mining is fundamental for the socioeconomic conjuncture of the municipality, the process of mineral exploration in the mining of the "High Feio" represents an exhaustive and rudimentary work, where work tools are not adequate and the garimpeiro protection does not exist. It was noticed that the environment has been adding losses due to the exploratory activity in the area. Therefore, we have the Federal Constitution of 1988 that ensures the ecologically balanced environment and regulates the sound maintenance of human life.
\end{abstract}

Keywords: Exploration, environment, federal constitution.

\section{INTRODUÇÃO}

A extração de recursos minerais tem se mostrado uma das principais fontes de riqueza econômica do Brasil ao longo de sua história. A mineração tem um papel essencial para a demanda

'Yuri Gomes de Souza, Departamento de Geografia, Universidade Federal de Campina Grande, Campina Grande-PB, Brasil.

${ }^{2} J o a ̃ o ~ L u c a s ~ P e r e i r a ~ C o b e l$, Departamento de Geografia, Universidade Federal de Campina Grande, Campina GrandePB, Brasil.

${ }^{3}$ Janaina Barbosa da Silva, Departamento de Geografia, Universidade Federal de Campina Grande, Campina Grande$P B$, Brasil. 
dos mais variados setores da indústria. No estado da Paraíba, é responsável pelo dinamismo socioeconômico devido à promoção interiorana de empregabilidade e renda, já que se caracteriza como uma das principais atividades extrativistas do Seridó paraibano (SANTOS, 2014).

Devido à geologia do município de Pedra Lavrada fazer parte da Província Pegmática ${ }^{4}$ da Borborema e sua estrutura geológica ter predomínio do embasamento cristalino (ASSIS; BARBOSA; MOTA, 2011), o setor econômico que abarca indústrias e garimpeiros fazem dessa área um local de alta viabilidade à exploração mineral. Logo, o desenvolvimento social e econômico oriundo da mineração é vigente, no entanto algumas consequências vêm impactando não apenas o meio ambiente, mas, sobretudo, a vida dos que dela sobrevive, os garimpeiros. Assim, devido à exploração de forma rudimentar e predatória no município de Pedra Lavrada-PB, confirma Silva et. al. (2016, p. 02) que:

\begin{abstract}
a degradação ambiental tem afetado não só os aspectos biofísicos (fauna, flora, poluição do ar, redução/exaustão de reservas minerais, como também a saúde de trabalhadores pela emissão de poeira (pequenas partículas e sílica); poluição sonora e visual; provocado abalos sísmicos, que por vezes provocam rachaduras nas edificações próximas; lançamento de fragmentos de rochas em virtude do uso de explosivos para o desmonte de rochas, o que coloca em risco não só os trabalhadores, mas também a população circunvizinha à jazida.
\end{abstract}

A Constituição Federal (CF) de 1988 detém de algumas disposições legais que visam resguardar o meio ambiente e controlar a exploração dos recursos naturais. A atividade de mineração é regulada pela $\mathrm{CF}$, pelo Código de Mineração e Leis específicas, além de atos normativos do Departamento Nacional de Produção Mineral - (DNPM), Ministério de Minas e Energia (MME) e Ministério do Meio Ambiente (CONAMA). Ademais, "qualquer alteração das propriedades físicas, químicas e biológicas do meio ambiente, afetando a biota, as condições estéticas e a qualidade dos recursos ambientais" deve ser considerada impacto ambiental (Resolução 1/86 CONAMA) (BARROS, 2017).

Com base no exposto, a presente pesquisa tem como objetivo central analisar a exploração mineral e suas consequências no município de Pedra Lavrada-PB. Além disso, como objetivos específicos têm-se: 1) Apresentar a morfologia do terreno com o uso do sensoriamento remoto; 2) Assinalar os impactos socioambientais da mineração no município de Pedra Lavrada-PB; 3) relacionar a atividade mineradora e a legislação ambiental brasileira. Afinal, o comportamento do ser humano para com o seu espaço de atuação cria uma relação de causa/efeito.

Para isso, a necessidade de investigar o trabalho que abarca a exploração mineral no tocante ao entendimento da fiscalização às atividades lesivas ao meio ambiente e ao ser humano, se faz importante. Sabendo-se que esse município tem seu potencial econômico conhecido desde a década

\footnotetext{
${ }^{4}$ São rochas holocristalinas que apresentam, pelo menos em parte, uma granulação muito grosseira, contendo como maiores constituintes minerais àqueles encontrados tipicamente em rochas ígneas comuns, mas com a caraterística de apresentarem extremas variações no que se refere ao tamanho dos grãos (JAHNS, 1982).
} 
de 1930, com foco em diversos bens minerais como feldspatos, quartzo, berilos, além de gemas como a turmalina elbaíta (VASCONCELOS, 2006), cabe ao Estado e os agentes responsáveis o papel de assegurar as atividades exploratórias à luz da sustentabilidade do meio ambiente e sadia qualidade de vida dos garimpeiros.

Assim, o trabalho se alicerçou na delimitação da área de pesquisa, no levantamento bibliográfico, análise empírica e apresentação da estrutura altimétrica e níveis de declividade do município de Pedra Lavrada-PB. A organização da pesquisa consiste em: introdução com a contextualização da temática e seus respectivos objetivos; na metodologia compondo a base de métodos e regras para a construção da pesquisa; os resultados e discussões com a bagagem de respostas aos objetivos; por fim, conclusões e referências.

\section{METODOLOGIA}

\section{1. Área de Estudo}

O município de Pedra Lavrada está localizado no estado da Paraíba, na região imediata de Cuité - Nova Floresta. De acordo com IBGE (2010) sua população é de 7.035 habitantes. Este município detém de um complexo mineralógico favorável à exploração (SALES, 2016), assim, o estudo partiu da análise da área de extração mineral neste município que está localizado no "Alto Feio", próximo a Cooperativa dos Mineradores de Pedra Lavrada Ltda - COOMIPEL, tendo como ponto de coordenadas geográficas: Latitude $6^{\circ} 44^{\prime} 55.76^{\prime \prime} \mathrm{S}$ e longitude $36^{\circ} 27^{\prime} 52.65^{\prime \prime} \mathrm{O}$, conforme aponta a Figura 01. 


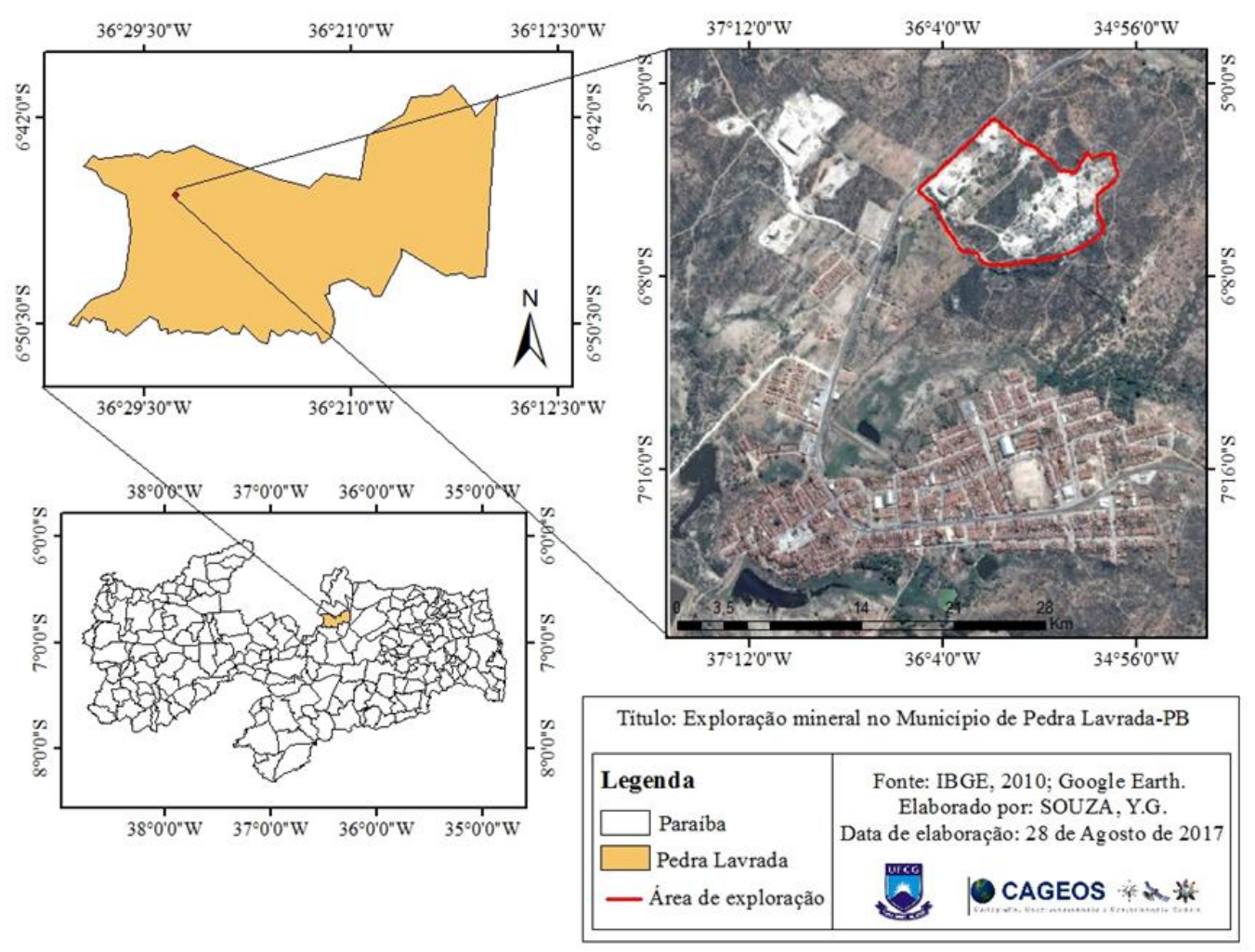

Figura 01: Localização da área de estudo. Fonte: Autor (2017).

\subsection{Procedimentos Metodológicos}

Para a realização do presente trabalho e com base nos objetivos supracitados foi realizado um levantamento bibliográfico como fundamento ao arcabouço teórico da pesquisa; realização de atividade de campo, sendo esta de extrema relevância no tocante a análise empírica dos elementos que permeiam a área da pesquisa, afinal como ratifica Mao Tsé Tung (1974) sem trabalho de campo ninguém tem direito de falar; aquisição, tratamento de imagem SRTM e elaboração de mapas.

O estudo de campo foi auxiliado pela Universidade Federal de Campina Grande através da disciplina de Pedologia do curso de Geografia sob orientação do docente responsável. O trabalho de campo foi importante para confrontar e/ou corroborar as informações anteriormente elencadas, com o intuito de identificar a exploração mineral e as suas consequências nesse Município. Para registro fotográfico utilizou-se câmera digital e a coleta de coordenadas geográficas foi feita com o receptor de sinal GPS (Global Position System) Garmin.

Aquisição de imagem

A imagem SRTM (Shuttle Radar Topography Mission) é disponibilizada pela plataforma gratuita Explorer da United States Geological Survey - USGS. Foi adquirido uma imagem com data de 23 de setembro de 2014 com ponto/órbita 215-65. 
Delimitação da área de estudo

Para a delimitação da área de estudo foi elaborada uma shapefile com o auxílio dos programas Google Earth Pro e Qgis 2.2 Valmiera, bem como o recorte do SRTM.

Tratamento de imagem e elaboração dos mapas

1. Reprojeção: O padrão de referência das imagens Radar obtidas através da USGS está orientado para o Hemisfério Norte em DATUM World Geodetic System (WGS) 1984 UTM Zona Norte, tendo a necessidade de fazer a reprojeção da mesma para o Hemisfério Sul, no caso a DATUM Zona 24S da América do Sul.

2. Hipsometria: De acordo com a delimitação da shapefile do município de Pedra Lavrada-PB, foi elencada a distribuição de sete classes, onde os valores variam entre 372 e 700 m. Logo, na área de estudo (local de exploração mineral), a altimetria varia entre 500 e $600 \mathrm{~m}$.

3. Declividade: Foi distribuída oito classes ao processamento no ArcGIS 10 pela ferramenta Slope. Logo, a classificação do relevo é de acordo com os valores de declividade apresentados no Tabela 01 .

Tabela 01: Classificação do relevo de acordo com a declividade. Fonte: (EMBRAPA, 2007).

\begin{tabular}{c|c} 
Classificação do relevo & Classificação da Declividade (\%) \\
\hline Plano & $0-3$ \\
\hline Suave-ondulado & $3-8$ \\
\hline Ondulado & $8-20$ \\
\hline Forte-ondulado & $20-45$ \\
\hline Montanhoso & $45-75$ \\
\hline Forte-montanhoso & $>75$
\end{tabular}

Para o recorte, tratamento das imagens de satélite e elaboração dos mapas utilizou-se os softwares Erdas Imagine 10 e ArcGIS 10, ambos licenciados para o Laboratório das Pós-graduações do Centro de Humanidades da Universidade Federal de Campina Grande (UFCG). 


\section{RESULTADOS E DISCUSSÕES}

Analisou-se as cotas altimétricas da delimitação da área de estudo, o "Alto Feio" que se encontra próximo a Cooperativa dos Mineradores de Pedra Lavrada Ltda - COOMIPEL, como auxílio ao entendimento morfológico. Verificou-se que a altitude que permeia se encontra entre 500 e 600 m, conforme aponta a Figura 02.

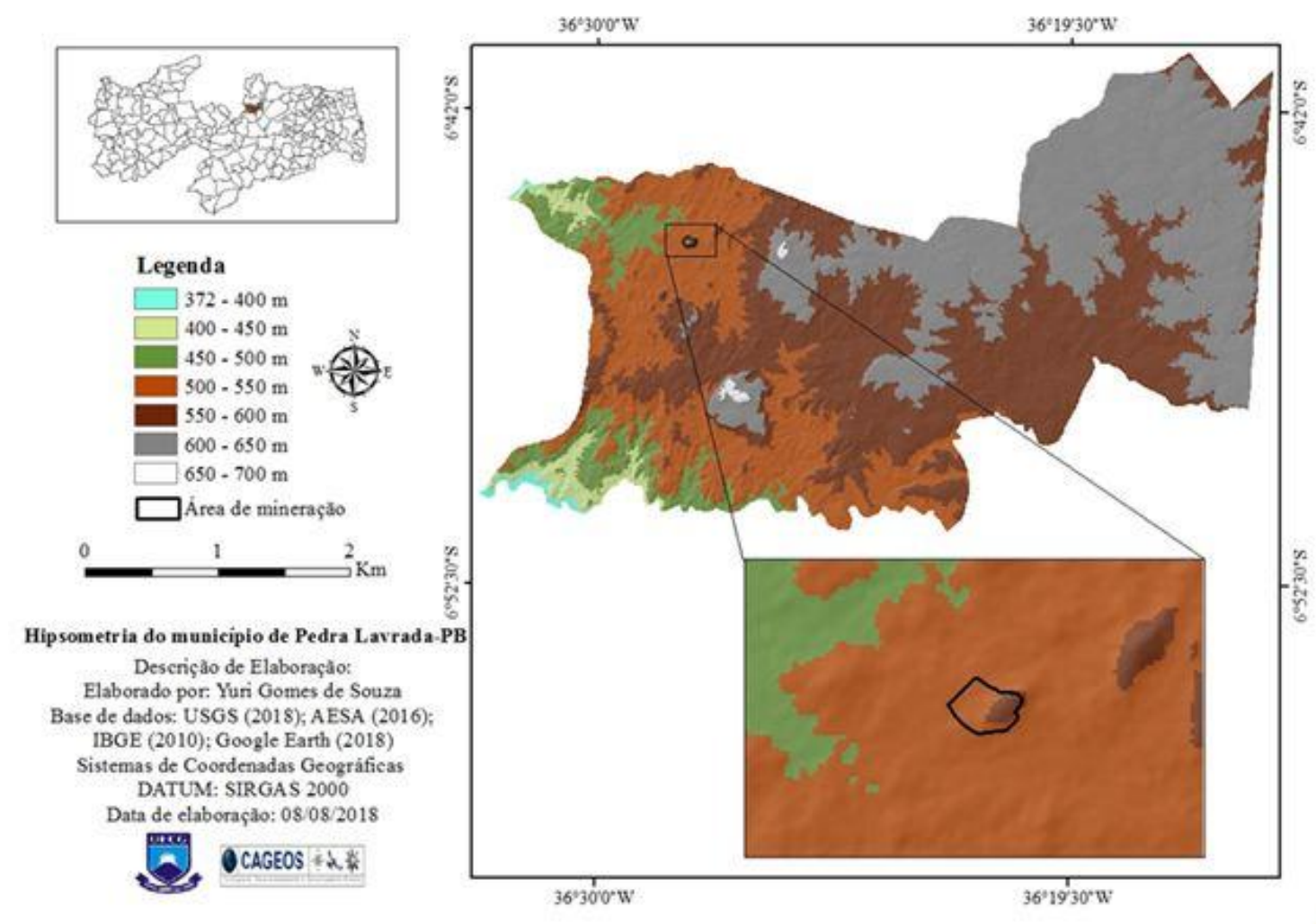

Figura 02: Hipsometria da área de estudo do município de Pedra Lavrada-PB. Fonte: Autor (2018).

Outra perspectiva analisada foi a declividade da área, onde verificou-se que grande parte dos valores que se encontram na delimitação estão entre 0 e $46 \%$, no qual o relevo é classificado como ondulado e montanhoso. Na Figura 03 tem-se que a porção oeste e leste o relevo é classificado entre $0-14 \%$ (relevo plano, suave ondulado e ondulado), já a norte e sul se encontram-se entre $20-46 \%$ (ondulado e montanhoso). 


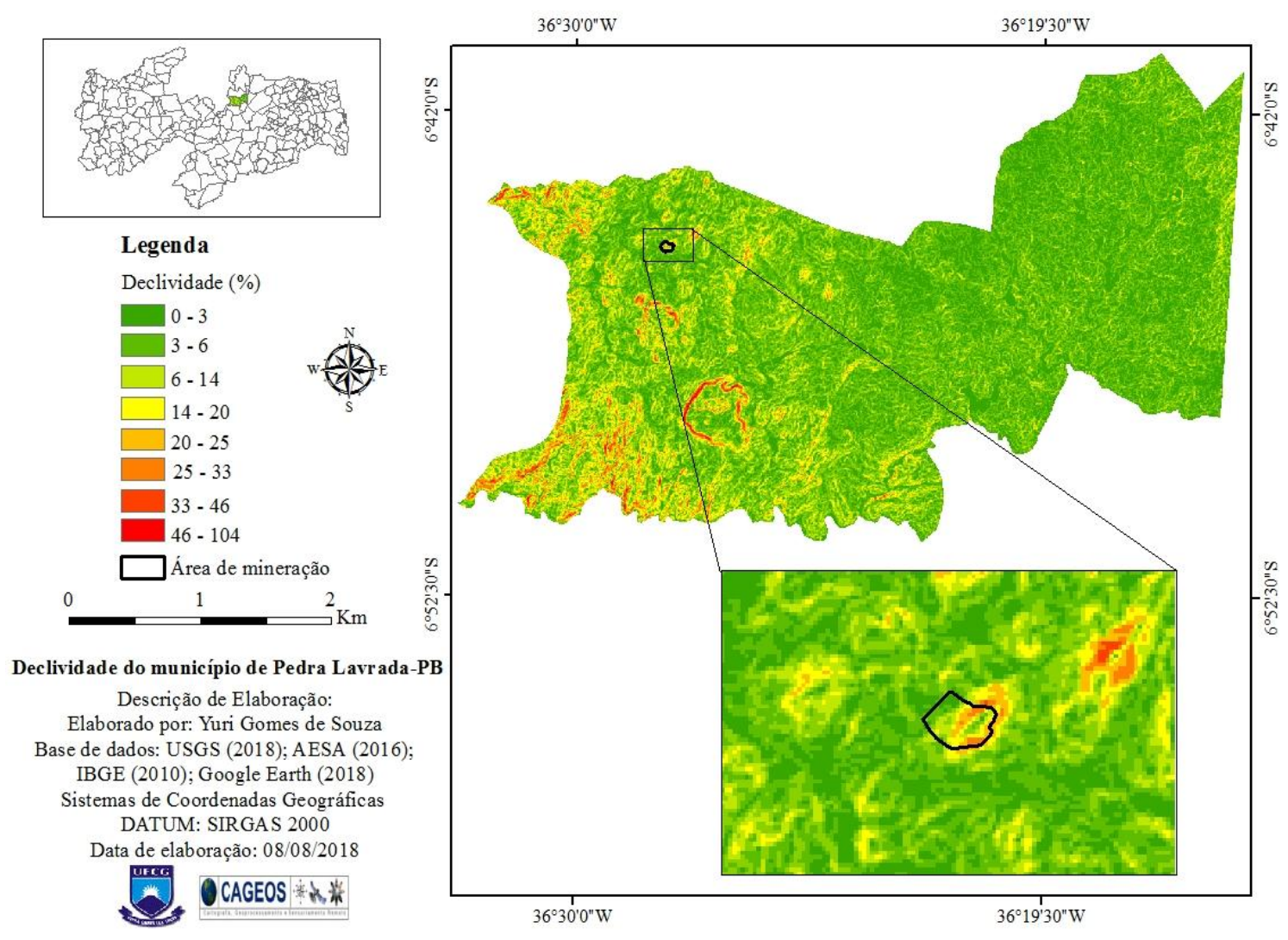

Figura 03: Declividade da área de estudo no município de Pedra Lavrada-PB. Fonte: Autor (2018)

Logo, corroborou-se em campo que o terreno que abarca esta área de lavra se apresenta como um relevo irregular e íngrime, além de que o acesso às áreas de extração dos minerais para pedestres e máquinas é dificutoso, pela própria constituição do relevo como pela alteração das diversas explosões já realizadas para o desmonte de rochas.

Partindo dessa premissa, a exploração mineral nessa área consiste, segundo Silva (2016), em quatro processos: 1) perfuração na rocha, e preenchimento dos mesmos com material explosivo; 2) detonação dos explosivos objetivando a fragmentação das rochas; 3) seleção e desbastação dos minerais; e 4) transporte para um "depósito" de minerais, de onde serão transportados por caminhões e caçambas para serem comercializados. Percebeu-se que, em seguida, segue a atuação dos garimpeiros na fase mais "elementar" e, manualmente, mais dificil em que consiste na seleção das rochas menores, no qual são transportadas em "carro de mão".

No tocante as vulnerabilidades lesivas à ação antrópica na lavra identificou-se: possibilidades de desabamentos de rochas, uma vez que alguns desses blocos são instáveis e apresentam fraturas descontínuas; garimpeiros sujeitos à acidentes nas profundas "banquetas", ou 
na própria área de lavra devido ao terreno irregular; trabalhadores enfrentando problemas na coluna cervical devido a atividade repetitiva e do transporte manual através do "carro de mão".

Com isso, confirmou-se a estrutura precária de trabalho dos garimpeiros, assim como os seus instrumentos de manuseio, sendo estes: A e D: Picareta e alavanca, respectivamente, servem para perfuração do pequenos corpos rochosos e fragmentação de minerais já detonados; B e C: "Garfo" e pá, respectivamente, para seleção dos minerais. Tais instrumentos são representados na Figura 04.

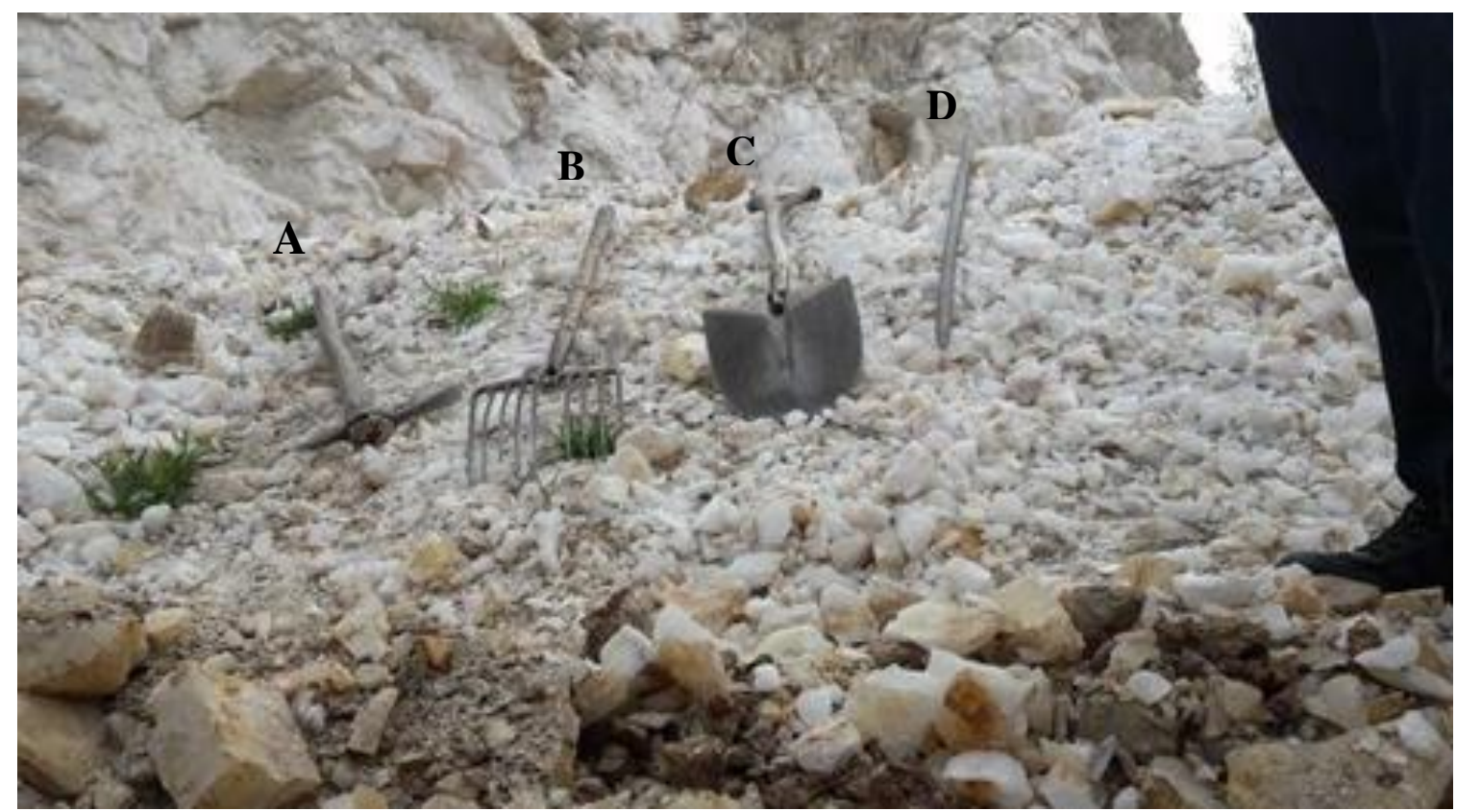

Figura 04: Ferramentas utilizadas pelos garimpeiros na mineração. Fonte: Arquivo Pessoal (2017).

Constatou-se também que não há o uso de Equipamento de Proteção Individual - EPI por grande parte dos trabalhadores, o que intensifica os problemas que podem sujeitá-los e o risco iminente de doenças. Torna-se preocupante esse cenário, uma vez que Lima (2013) confirma que segundo dados da Secretaria de Saúde do Estado da Paraíba, no município de Pedra Lavrada já foram registrados 5 (cinco) casos de mortes em decorrência da silicose no período de 2000 a 2012. Para exemplificar, a Figura 05 retrata um dos momentos do processo de exploração mineral por parte dos trabalhadores sem nenhuma proteção cabível à atividade. 


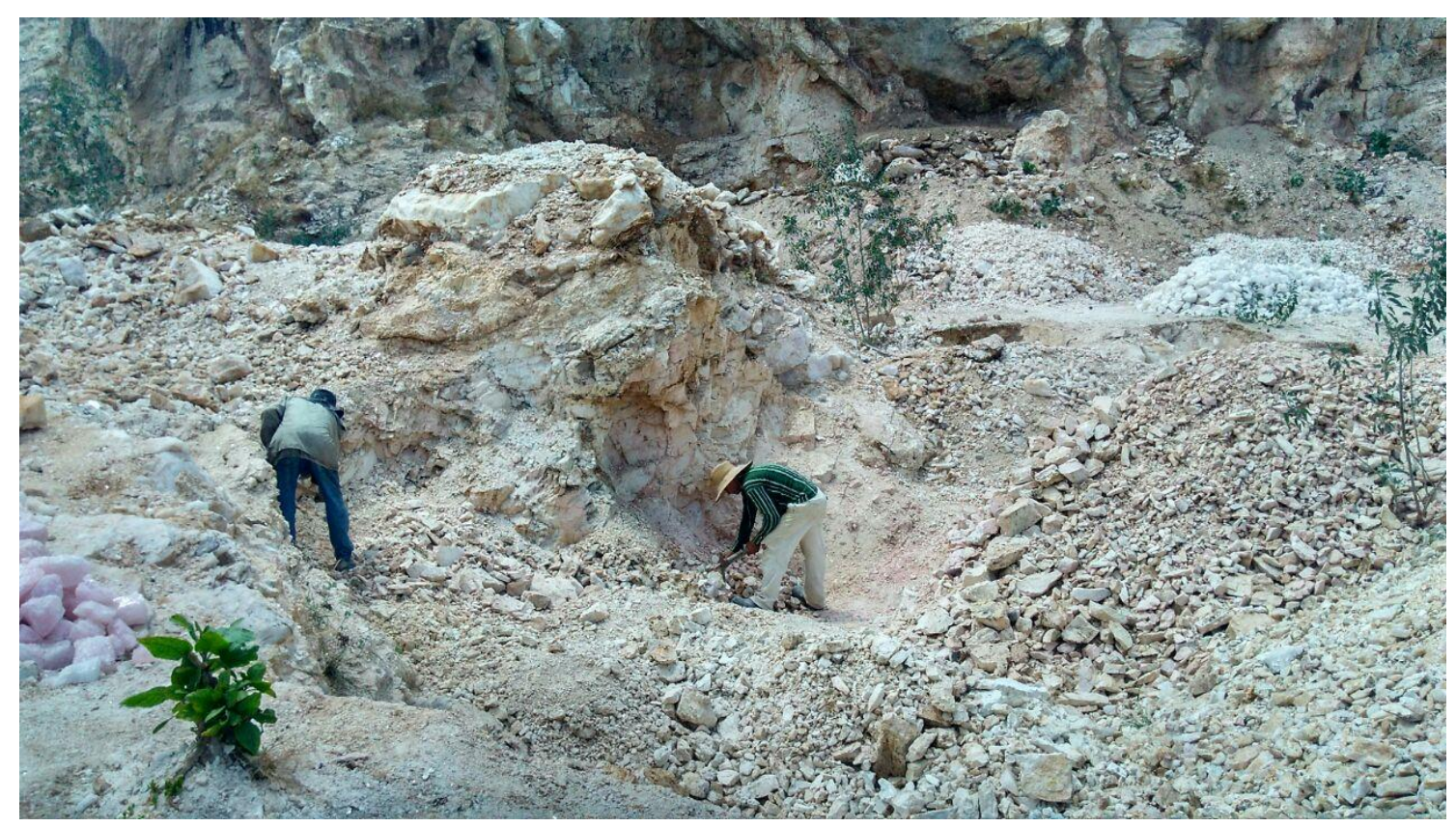

Figura 05: Garimpeiros em processo de quebra e seleção dos minerais. Fonte: Arquivo Pessoal (2017).

Além dos prejuízos sujeitando a saúde do ser humano nessa laboridade, pode-se apresentar também os danos ambientais causados pela mineração, podendo destacar: retirada de vegetação para uso e ocupação da área; mina intensamente explorada e abandonada após uso, causando impacto à paisagem e risco ao ser humano (possibilidade de acidente); poluição do ar através de partícular de poeira e sílica (paisagem esbranquiçada); poluição sonora; processos erosivos da superfície terrestre; crateras expostas em virtude da exploração e detonação maciça; desequilíbrio dos ecossitemas próximos às jazidas devido a retirada do meio biótico e de elementos abióticos, ambos essenciais à vitalidade de um habitat.

Com base nas consequências enfrentadas pelo meio humano e ambiental frente ao processo de mineração tem-se algumas medidas legais que podem ser atribuídas como amparo lúcido às boas práticas da mineração, as quais visam somar o desenvolvimento econômico e o progresso da sociedade à luz de um ambiente sustentável. Destarte, cabe ao Estado regulamentar e fiscalizar, e aos exploradores do espaço além do seu papel econômico é seu dever contribuir para a sustentabilidade do ambiente explorado.

No que diz respeito a Legislação Brasileira, a Resolução $n^{\circ} 001$ do Conselho Nacional do Meio Ambiente (CONAMA), publicada no Diário Oficial da União em 17 de Fevereiro de 1986, em seu artigo $1^{\circ}$ prevê que:

“Art. $1^{\circ}$ - [..] considera-se impacto ambiental qualquer alteração das propriedades físicas, químicas e biológicas do meio ambiente, causada por qualquer forma de matéria ou energia resultante das atividades humanas que, direta ou indiretamente, afetam: I - a saúde, a segurança e o bem-estar da população; II - as atividades sociais e econômicas; III - a biota; 
IV - as condições estéticas e sanitárias do meio ambiente; V - a qualidade dos recursos ambientais."

Utilizando a hermenêutica literal do artigo citado, identificou-se a extração mineral como exaustiva, onde esta atividade modificadora do espaço gera impactos oriundos da ação antrópica, contrariando os incisos I, II, III IV e V do referido art. $1^{\circ}$. Assim, pode-se identificar alguns problemas constatados de acordo com cada inciso supracitado: I- O trabalhador em sua laboridade está sujeito às doênças pulmorares devido a exposição às partículas de poeira; II- A cidade está subjulgada ao poder da atividade econômica da mineração, com significativa parte da população submissa a esta atividade; III- Desaparecimento de espécies da fauna e flora, com decapeamento da vegetação, migração de animais, desequilibrando a biodiversidade do local; IV- Degradação da paisagem e exposição de rejeito mineral em locais inadequados; V- Em decorrencia da exploração maciça os minerais não são bem aproveitados, muito deles desperdiçados como é o caso do quartzo rosa, uma vez exposto ao sol perde sua cor e seu valor econômico.

Para isso, é importante destacar também a responsabilidade ambiental que cabe ao ser humano no que tange o uso e ocupação do espaço de forma intensa. Barros (2017) aponta que a Lei $\mathrm{n}^{\circ}$ 6.938, de 31 de agosto de 1981, institui a Política Nacional do Meio Ambiente, quando esta estabelece, por meio de seu art. $2^{\circ}$, que essa Política tem como objetivo a preservação, melhoria e a recuperação da qualidade ambiental. Com isso, a CF/88, em seu art. 225 , $\S 2^{\circ}$ e $\S 3^{\circ}$, e a Lei 6938/81, em seu art. $2^{\circ}$, estabelecem que:

“Art. 225. [...] $\S 2^{\circ}$ Aquele que explorar recursos minerais fica obrigado a recuperar o meio ambiente degradado, de acordo com a solução técnica exigida pelo órgão público competente, na forma da lei."

“Lei 6938/81 Art. 2 Para efeito deste decreto são considerados como degradação os processos resultantes dos danos ao meio ambiente, pelos quais se perdem ou se reduzem algumas das suas propriedades, tais como a qualidade ou capacidade produtiva dos recursos ambientais."

Embora a realidade vigente precise de uma maior atenção perante às disposições legais de trabalho e de exploração mineral, sabe-se também da importância social e econômica que essa atividade promove a esse Município. Segundo Assis, Barbosa e Mota (2011) a atividade mineral no ano de 2010 proporcionou a Pedra Lavrada-PB a $4^{\mathrm{a}}$ posição do Estado da Paraíba em arrecadação da Compensação Financeira pela Exploração Mineral (CFEM).

\section{CONSIDERAÇÕES FINAIS}

Diante dos estudos realizados, conclui-se que o município de Pedra Lavrada-PB, tem relevo com altitudes que variam entre 372 e 700m, comum ao Planalto da Borborema. Com declividade no 
“Alto Feio" de 20 a 46\%, a irregularidade do terreno se apresenta como ondulado e montanhoso, no qual são características marcantes da paisagem local.

Quanto a atividade mitigadora extrativista, ocorre de forma rudimentar e predatória, trazendo como principais consequências: diminuição espacial da Caatinga; decapeamento da vegetação local; passível aumento do processo erosivo; exposição do rejeito de forma inadequada; diminuição da qualidade do ar a partir das partículas de poeira e trabalhadores sujeitos aos prejuízos à saúde.

Acredita-se na importância da mineração para o desenvolvimento social e econômico da população de Pedra Lavrada-PB. Contudo, há ressalvas em seu desenvolvimento exploratório quanto ao cumprimento da Política Nacional de Meio Ambiente trazendo equilíbrio à produção/ambiente: 1- fiscalizar com mais veemência as práticas desenvolvidas na lavra; 2 utilização de métodos e técnicas para diminuir os impactos socioambientais, como: orientação e atenção com os trabalhadores em seu labor; explosões previamente pensadas com base em objetivos; rochas armazenadas em locais adequados.

Desse modo, faz-se essencial pensar alternativas para as práticas na mineração, uma vez que o equilíbrio entre o progresso econômico, o desenvolvimento social e a sustentabilidade dos recursos minerais cheguem em destaque enquanto uma atividade economicamente possível, socialmente justa e ambientalmente responsável.

\section{REFERÊNCIAS}

AB'SABER, A.N. Os domínios morfoclimáticos na América do Sul: primeira aproximação. Geomorfologia, v.53, 1977. p. 1 - 23.

ASSIS, H. F. S.; BARBOSA, J. A. A.; MOTA, T. S. Avaliação dos impactos ambientais provocados pela atividade mineradora no município de Pedra Lavrada-PB. Revista Âmbito Jurídico, N 90-Ano XIV, 2011, p. 1-16.

BRASIL. Constituição de 1988. Constituição da República Federativa do Brasil. Brasília, DF: Senado Federal: Centro Gráfico, 1988. p. 1 - 292.

BRASIL. IBGE. Censo Demográfico, 2010. Dispinível em: <www.ibge.gov.br>. Acesso em: 08 ago. 2018.

BRASIL. Ministério do Meio Ambiente. Disponível em: <www.mma.gov.br>. Acesso em: 08/08/2018.

BARROS, J. N. Legislação ambiental aplicada à mineração. Cruz das Almas, BA: UFRB, 2017. p. $1-86$. 
DANTAS, J. A atuação das cooperativas na atividade mineral no seridó paraibano: os casos da coopicuí e coomipel. Dissertação (Mestrado) - Curso de Pós Graduação em Desenvolvimento Regional, Universidade Estadual da Paraíba, Campina Grande, 2017. p. 1 - 127.

EMBRAPA - Empresa Brasileira de Pesquisa Agropecuária. Preservação e uso da Caatinga / Embrapa Informação Tecnológica / Embrapa Semiárido. Brasília: Embrapa Informação Tecnológica, 2007. p. 1 - 39.

JAHNS, R. H. Internal evolution og granitic pegmatites. In Granites Pegmatites in Science and Industry (P. Cerný, ed.). Mineralogical Association of Canada, Short Course Handbook, v. 8, p. 293-346, 1982.

LIMA, H. C. A trajetória do setor mineral no município de pedra lavrada - PB: uma análise das ações públicas para pensar o desenvolvimento. Dissertação (Mestrado) - Curso de Pósgraduação em Desenvolvimento Regional, Universidade Estadual da Paraíba, Campina Grande, 2013. p. $1-128$.

SALES, E. D. G.; SANTOS, L. C. M. L.; VIEIRA, F. F. Mapeamento geológico, zoneamento mineral e potencial econômico do pegmatito alto serra branca, Região de Pedra Lavrada, Seridó paraibano. João Pessoa: Smin, 2016. p. 1 - 10.

SANTOS, A. M. Avaliação das práticas os mineradores e seus respectivos impactos socioeconômicos e ambientais no município de Pedra Lavrada - PB. 2014. TCC (Graduação) Curso de Curso de Licenciatura Plena em Geografia, Universidade Estadual da Paraíba, Campina Grande, 2014. p. 1-35.

SILVA, J. A. L. et al. Avaliação dos impactos socioambientais advindos da extração mineral em áreas próximas aos centros urbanos: estudo de caso no município de Pedra LavradaPB. Revista Espacios, Caracas, 2016. p. 1-12.

VASCONCELOS, S. A. O uso do território do município de pedra lavrada - PB pela mineração: Elementos de Inserção como Lugar do Fazer no Contexto Atual da Globalização. 2006. 216. Dissertação (Mestrado) - Curso de Curso de Mestrado e Doutorado em Geografia, Universidade Federal de Pernambuco, Recife, 2006. 216 p.

Recebido em: 13/04/2019

Aceito para publicação em: 25/05/2019 